aside the fatal cases which I hare already spoken of, I was enabled to tabulate in the paper already referred to the particulars of attacks of chorea affecting 69 children. Of these, 50 were girls, 19 boys. To take the more recent experience of the same hospital, and as a whole, without distinction of physician, I have learned from Dr. Chaffey, the present registrar, that in the last seven years 472 patients were admitted with chorea-336 girls, 136 boys. Thus embolism and chorea differ in their incidence. One has little sexual preference. Of the other the sexual preference is strongly marked.

Next as to age. Embolism is connected with antecedent disease-rheumatism or other. Acute rheumatism is less frequent in childhood than in early adult life, and the other changes to which embolism is due are mostly more chronic and of still later occurrence. Thus embolism belongs rather to adult life than to childhood, while chorea belongs rather to childhood than adult life. At St. George's Hospital, where patients of all ages are admitted, the results of embolism were found on an average once in 46 post-mortems. At the Hospital for Sick Children, where the patients range from two to twelve, these results were found once in 169 postmortems. Thus embolism is nearly four times more frequent in a mixed community than in a community of children. At St. George's the patients admitted with embolism varied in age, the males from 15 years to 74 years, the females from 3 years to 66 years. The average age of the males was 38 , of the females 29, of both together 34. As to chorea, the ages of the two male subjects was in each case 11 years. That of the females varied from 7 years to 54 years, giving an average of 17 , raised thus high by what may be termed the accidental or at least the exceptional inclusion of the case fatal at the unusual age of 54. The average of the male and female cases together was 16. Thus from the experience of a general hospital, where there is no exclusion on the ground of age, persons die with embolism at a mean age of 34 , with chorea at a mean age of 16 , the last figure being no doubt higher than it would commonly be owing to the exceptional case to which reference has been made. Chorea thus belongs to an earlier period of life than embolism.

To recapitulate the evidence which has been adduced for and against the embolic origin of chorea.-When chorea is associated with acute rheumatism, endocarditis often precedes the nervous affection. When chorea arises otherwise, as in fright, the nervous affection may precede any cardiac disturbance, the valvular lesion in such cases being, so far as clinical observation can show, not the first departure of the disease, but acquired in its course. Chorea is apt to occur in neurotic families. Pathologically, though the lesions of chorea are mainly vascular and perivascular, as are those of embolism, yet the parallelism does not extend into particulars. The distended vessels of chorea almost invariably contain blood-corpuscles, not fibrine; and the lesions have a bilateral symmetry, and proneness to repeat themselves in certain places functionally chosen-habits consistent with an origin in nervous disturbance, not with one in embolism and accident. After death with chorea the embolic process was found to have occurred in some part of the body in a tangible proportion of cases - 3 in 27 . But taking the frequent concurrence of valvular disease and chorea, however accounted for, the proportion of embolism is probably no more than would be reckoned on as due to the heart disease, even though it were presumed that the accident had no connexion with the nervous disorder. That there is no necessary connexion between embolism and chorea appears by the absence of the disease among the recognisable consequences of embolism. One hundred and forty-seven cases in which this lesion was found at St. George's gave but one of chorea; among children chorea presents itself with more frequency, but, nevertheless, 3 in 158 represents the total concurrence. Next, embolism is distributed between the sexes not very unequally, the male taking the larger share. Chorea is about three times more frequent in the female than in the male.

Finally, it has been shown that embolism selects a later time of life than chorea, the average difference being probably under-stated by that between thirty-four years and sixteen. This selection by chorea of females and the young, while embolism displays no such partiality, is not conclusive against their relation as effect and cause, though it tells in that direction. It is conceivable that female children may hare a special susceptibility, in virtue of which they derelop chorea from a cause which is insufficient to produce it in the male. Alcohol causes paraplegia in the female, seldom in the male; delirium tremens in the male, seldom in the female. It is not improbable that some of the causes of chorea may be presented equally to both sexes, but affect them unequally; and so it may be with embolism. But embolism is a coarse, mechanical accident, the consequences of which are not likely to be dependent on special susceptibilities. A storm of emotion may shake or shatter the more tender structure and leave the tougher unhurt; but we have no reason to attribute any such partiality of effect to theimpaction of clots. The probability is that if chorea is a result of embolism, where embolism is there will be chorea. Putting all the evidence together, it appears to me to be conclusive against the embolic origin of chorea. Dr. Money's artificial embolism caused many varieties of abnormal or forced movement, of which chorea was one. If the right place be irritated, we have no reason to suppose that the irritant must always be the same. The irritation, for aught we know, may begin in one case in the vessel and affect the nerve, and in the other begin in the nerve and affect the vessel. The artificial process may be somewhat similar in its results to the natural one, and yet the modus operandi of nature and art be essentially different. In both we can recognise plugged or distended vessels, and must infer the irritation of certain motor centres, but we need not assume a resemblance in all particulars or identity of origin. It by no means follows that because choreic movements are among the results of artificial embolism in animals, chorea as a disease is the result of embolism in man. Dr. Money, in his valuable and judicious paper, carefully abstains from drawing this conclusion, and I venture to think that the facts I have adduced justify his caution in this respect.

Chesterfield-street, Mayfair, W.

NOTE ON

\section{ANKLE-CLONUS AS A SYMPTOM IN CERTAIN FORMS OF NERVOUS DISEASE.}

\section{BY W. S. PLAYFAIR, M.D., LL.D., F.R.C.P.}

I HAD not the advantage of being present at the discussion at the Medical Society at which Dr. Gowers read his very interesting paper on the "Diagnostic Value of the so-called Tendon Reflexes." In this Dr. Gowers maintains, but with more reservation than in his book on "Diseases of the Spinal Cord," that the occurrence of distinct ankleclonus may generally be taken as a proof that a given case of hysterical paraplegia, as well as other cases of supposed functional nervous disease, is really of structural origin. If this fact could be relied on as a certain sign of such structural changes in the spinal cord as preclude the hope of permanent cure, or of such amelioration in the walking powers as is tantamount to it, it would be an immense help to those who have to face the almost insuperable difficulties of diagnosis which sometimes present themselves; for the symptom is one easily tested. The fact that I have chanced to direct attention in THE LANCET to the so-called "Weir Mitchell Method" of treating certain forms of functional nervous disease in women has given me the opportunity of seeing many obscure cases of this kind, and I have naturally had my attention directed very closely to this point in the hope of avoiding an error of diagnosis. In many doubtful cases I have had the advantage of consultation with Dr. Buzzard, as well as with other neurologists equally distinguished, and to some of these Dr. Buzzard referred in the discussion which followed the reading of Dr. Gowers' paper, when be said he had seen with me "ankle-clonus, quite indistinguishable from that which was characteristic of lateral sclerosis, occur in many cases of hysterical paraplegia, in which, on recovery, it ceased to be elicited." I am perfectly satisfied that if the presence of true clonus should always be taken as a contraindication to a well-directed and systematic effort to cure certain cases of functional or "nutritional" nerrous disease, as Dr. Gowers so wisely suggests they should preferably be called, then the serious error would be fallen into of levving untouched cases quite within the possibility of cure. Dr. Gowers says: "I have never seen an unquestionable instance of it"; I can positively state, on the other hand, that I have 
seen not one but many, cases in which, at first, a perfectly characteristic clonus was obtainable, and in which, under the improved nutrition and increased strength following systematic treatment, this symptom steadily and progressively diminished, being constantly tested from time to time, until at last it could not be elicited at all. In these I commenced treatment with doubt and anxiety on account of the presence of the clonus; and, had it not been for Dr. Buzzard's encouragement, some of them would have remained uncured to this day, so far as I am concerned. As was only natural, therefore, I paid very particular attention to this point, and $I$ cannot be mistaken as to the issue.

It is needless to burden this note with cases, but I may refer, in illustration, to two marked examples which I well remember.

Mrs. D-_, aged fifty-two, completely paralysed in her lower extremities for twenty-five years. Has never moved off her couch all this time except occasionally across the room on crutches. Exaggerated knee-jerk and distinct clonus. A year has elapsed since I last saw this patient, and then it was impossible to elicit any clonus at all. She has since remained perfectly well, is able to take long walks, to visit amongst her friends, \&c.

Miss I-_-, aged thirty-five. Seventeen years practically bedridden. Here, again, clonus was quite distinct. Two years have elapsed since this patient was under my care.

I select these cases because Dr. Buzzard saw them with me, so that there can be no doubt that the clonus noted was not the "spurious foot-clonus" Dr. Gowers refers to.

Dr. Gowers says very pertinently: "Cases of hysterical paraplegia with excess of myostatic contraction get better, but do they get well? The patients regain the power of walking, but not of walking well; they remain what is popularly called bad walkers, soon tired, even with standing." This seems to me exceedingly probable, but it is obvious that if such patients can be made so far better that they discard their crutches, give up their beds, and cease to be the miserable invalids so many of them are, then they get, at any rate, well enough to justify any efforts at cure, in spite of the pre-existence of an excess of myostatic irritability. I by no means intend to under-estimate the grave import of this symptom; all I contend for is that it must not be too exclusively relied upon in settling the diagnosis of a doubtful case. I heartily wish, for the comfort of those who are responsible for the diagnosis, that it could. The solution of the riddle will probably be found in the direction of Dr. Gowers' suggestive remark: "That in many of these cases there must be a change, and a considerable change, in the nutrition of the nerve elementssometimes, it may be, springing out of a mere functional derangement, but always maintaining and increasing that derangement." It is because of this, $I$ believe, that the systematic treatment of these cases often has such surprising results. Beyond and above the moral effects of removal from unwholesome domestic surroundings, and the personal influence of the medical attendant, the improved nutrition of her whole body is such as no one can believe who has not seen the results, and with this increased nutrition comes the disappearance of the symptoms. But that there is always a considerable risk that in old-standing cases of this specia form of neurosis the impaired nutrition of the central nervous system may have led to the establishment of progressively increasing structural disease is a fact which, I believe, in creased experience in this very obscure class of disease will prove to be the case. This, $\mathrm{I}$ cannot doubt, is the true explanation of the occasional want of success in the treatment of cases in which the diagnosis of so-called "functional " disease was beyond question. This everyone who has tried to cure many of these cases must have met with; nor is it any reason why the attempt should not be made. Hitherto, when we have had to deal with a case of "hysterical" or "functional" disease, we have all been too much in the habit of simply establishing the fact, forgetting that patients come to us, not to be diagnosed, but to be cured. If the patient have the good fortune to come under a "faith cure," or to go to Lourdes, or to fall into the hands of anyone, whether a regular or irregular practitioner, who has sufficient moral influence over her, now and again a cure of this lamentable illness may occur in a hap-hazard sort of a way; otherwise she may linger on for half a lifetime, a burden to herself and all who come in contact with her, but no medicine will touch her case. Whereas, as a matter of fact, she is suffering from a class of disease which, rationally and scientifically treated, is more completely within the resources of our art than almost any of the diseases which "flesh is heir to," although doubtless the cure requires an enormous amount of patient work.

ON THE

\section{IMIMEDIATE OCCLUSION OF THE CORNEAL WOUND AFTER EXTRACTION OF CATARACT. ${ }^{1}$}

\section{BY DR. GALEZOWSKI.}

THE operation of extraction of cataract has made of late rery rapid progress, and the results obtained now are most satisfactory, failures being only seen in cases altogether exceptional, such as traumatisms, or when the general condition of the patient is extremely weak and broken down. The success of the operation depends, without doubt, on the manner of operating, as well as on the subsequent care and post-operative dressings. After the labours of Jacobsen, Mooren, and De Graefe, ophthalmologists throughout the world adopted the principle advocated by these eminent German authors - that, in the extraction of cataract, it was necessary to excise the iris, as by so doing the suppuration of the corneal flap was prevented; and they used to practise it either on the peripheral border (sclero-corneal) or on the sclerotic proper, thus enabling the wound to take almost linear form and become easy of coaptation. This was the opinion that prevailed among ophthalmologists, and which has been accepted until now by the majority of surgeons.

I was the first who, in 1882, had the idea of returning to the extraction of cataract without incision and avoiding the incision of the sclerotic and placing it altogether on the cornea, seeing that suppuration supervened after extraction in spite of previous excision of the iris, as recommended by Mooren, or the extraction proper. The results of this operation have been more favourable than those of De Graefe, as it has been demonstrated by my memoir to the Société de Chirurgie in 1882, and also by my report to the Société Française d'ophthalmologie and to the Congress of French Surgeons. In all these reports I have tried to demonstrate three important points, and upon. which I insist to-day more than ever. 1 . That if I abandon the German method and incline myself to the French method, it is because there are in my incision and modus operandi other conditions of execution altogether peculiar, that allow me to consider it as my own special procedure. 2. That the excision of the iris cannot and must not be abandoned entirely, but must be reserved for cases altogether exceptional, such as when the iris is adherent, posterior synechix, when the lens is dislocated or the nucleus floating, when the capsile is opaque, and when it is to be extracted at the same time as the lens. 3. That the results of the operation depend as much on the manner in which it is practised as on the post-operative dressings. In a work I am now preparing, and which follows my studies on cataract in general, I intend to derelop successively all the questions that relate to my first two points. My third proposition, which relates to the post-operative dressing plays a very important $r \hat{b} l e$, as I have already stated, and has engaged my attention for a long time. I was constantly endeavouring to ascertain the cause that brought on suppuration of the wounds in certain individuals without any plausible reason. The general hygienic conditions, atmospheric influences, and morbid constitutions have been analysed and computed successively, but nothing could explain these accidents, which arose sometimes where one least expected them. Returning to the principles of Pasteur, that suppuration could not be produced except by the poisoning of the wound by microbes, $I$ thought that the tears might, even in normal conditions of life, contain microbes, and that in certain pathological conditions they could multiply and be brought into contact with the corneal wound, infect it, and bring on suppuration in it. This question could only be elucidated by delicate microscopical observation of the tears. I enentrusted one of my pupils, Dr. Salterain, of Monte Video,

1 Memoir read at the Academy of Medicine, Oct. 6th, 1385. 